\title{
Restitución e indemnización a sujetos indeterminados, cy-près y acciones de clase ${ }^{\star}$
}

\author{
Restitution and Compensation to Indeterminate Individuals, \\ Cy-Près and Class Actions \\ Restituição e indemnização a sujeitos indeterminados, cy-près \\ e ações coletivas
}

\author{
JaVier ESTEBAn RodríGuez DieZ \\ María Elisa ZaVAla ACHURRA ${ }^{* \star *}$
}

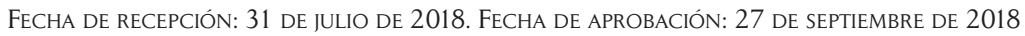

DoI: http://dx.doi.org/10.12804/revistas.urosario.edu.co/sociojuridicos/a.7028

Para citar este artículo: Rodríguez Díez, J. E. E Zavala Achurra, M. E. (2019). Restitución e indemnización a sujetos indeterminados, cy-près y acciones de clase. Estudios Socio-Jurídicos, 21(1), 151-176. Doi: http://dx.doi.org/10.12804/ revistas.urosario.edu.co/sociojuridicos/a.7028

\section{RESUMEN}

El presente artículo ofrece una perspectiva histórico-comparativa sobre la posibilidad de admitir acciones de clase en favor de sujetos indeterminados. El punto de partida para este análisis es la doctrina del cy-près del common law, al mostrar su aplicación a las acciones de clase y las objeciones que ha enfrentado. Luego se ofrece un contraste con las jurisdicciones de derecho civil continental, donde la posibilidad de compensar a sujetos indeterminados se desvaneció con el paso del tiempo, dando lugar a un sistema basado, predominantemente, en el public enforcement. Finalmente, se ofrece una visión crítica de la reciente introducción de la doctrina del cy-près en jurisdicciones latinoamericanas, donde se considera el fracaso al derivar algunas precauciones básicas de la experiencia comparada.

Palabras clave: acciones de clase, interés difuso, doctrina del cy-près, resarcimiento fluido.

* Al momento del envío del presente trabajo, este no ha sido presentado en ningún congreso ni ha sido escrito para una ponencia.

** Abogado, licenciado en Derecho por la Pontificia Universidad Católica de Chile y doctor en Derecho por la Erasmus Universiteit Rotterdam. Profesor de Derecho Romano de la Facultad de Derecho de la Pontificia Universidad Católica de Chile, Santiago, Chile. El presente trabajo ha contado con el financiamiento del Proyecto Fondecyt No. 1180022 de 2018, del cual el autor es coinvestigador. ORCID: https://orcid.org/0000-0002-4015-1191. Correo electrónico: javier. rodriguezdiez@uc.cl

*** Abogada, licenciada en Derecho por la Pontificia Universidad Católica de Chile. Profesora de Derecho Internacional de la Facultad de Derecho de la Pontificia Universidad Católica de Chile, Santiago, Chile. ORCID: https://orcid.org/0000-0002-0202-2604. Correo electrónico: mezavala@uc.cl 


\section{ABSTRACT}

This article offers a historical and comparative perspective on the possibility of admitting class actions in favor of indeterminate individuals. The starting point for this analysis is the common law's cy-près doctrine, showing its application to class actions and the objections that it has faced. A contrast is then drawn with civil law jurisdictions, where the possibility of compensating indeterminate individuals has receded in the course of time, giving place to a system predominantly based on public enforcement. Finally, a critical view of the recent introduction of the cy-près doctrine in Latin-American jurisdictions is offered, on account of their failure to draw some basic precautions from the comparative experience.

Keywords: Class actions, absent class members, cy-près doctrine, fluid recovery.

\section{RESUMO}

O presente artigo oferece uma perspetiva histórico-comparativa sobre a possibilidade de admitir ações coletivas em favor de sujeitos indeterminados. O ponto de partida para esta análise é a doutrina do cy-près do common law, mostrando sua aplicação às ações coletivas e as objeções que tem enfrentado. Logo se oferece um contraste com as jurisdições de direito civil continental, onde a possibilidade de compensar a sujeitos indeterminados desvaneceu-se com o passo do tempo, dando lugar a um sistema baseado predominantemente no public enforcement. Finalmente, se oferece uma visão crítica da recente introdução da doutrina do cy-près em jurisdições latino-americanas, considerando o fracasso ao derivar algumas precauções básicas da experiência comparada.

Palavras-chave: ações coletivas, interesse difuso, doutrina do cy-près; ressarcimento fluido. 


\section{Introducción}

El problema de las restituciones o indemnizaciones en favor de sujetos indeterminados no es, en ningún caso, una novedad de nuestro tiempo. Como se verá más adelante, ya la escolástica española se planteaba el problema de cómo restituir las ganancias ilícitas obtenidas de manos de sujetos indeterminados. Sin embargo, estas ideas se perdieron gradualmente en el derecho civil continental, lo que llevó a atender a las conductas ilícitas que afectaran a sujetos indeterminados, ante todo, desde la responsabilidad infraccional, lo que hizo que el foco de atención se desplazara al problema de la determinación y cuantía de la multa, relegando a un segundo plano el problema de indemnizar a los afectados por el ilícito. Esta es la suerte que ha corrido la responsabilidad asociada a ilícitos anticompetitivos, por mencionar un caso característico, donde los sujetos afectados suelen ser indeterminados y donde el derecho civil continental privilegia, ante todo, el public enforcement, es decir, la persecución por parte de órganos estatales con fines sancionatorios. De esta forma, en la mayoría de los sistemas de derecho civil continental, no ha habido un desarrollo importante de la indemnización a sujetos indeterminados, lo que puede explicarse tanto por la efectiva función disuasoria que cumplen las multas en muchos países europeos (y la consiguiente preponderancia del public enforcement), como por la reticencia a subvertir el principio de certidumbre y personalidad en la atribución del daño. Por lo mismo, prácticamente todos los sistemas europeos que contemplan acciones colectivas con función indemnizatoria establecen una modalidad opt-in, en virtud de la cual solo los sujetos que se hagan parte en el juicio y acrediten pertenecer a la clase afectada pueden ser indemnizados.

Distinto es el caso de los países del common law, en particular Estados Unidos, donde en las últimas décadas se han desarrollado mecanismos que buscan distribuir montos restitutorios e indemnizatorios en favor de sujetos indeterminados, propiciando distintos mecanismos para identificar a los consumidores afectados y, cuando ello no fuera posible, para buscar una forma alternativa para indemnizarlos que no implique su identificación. En el caso de los ilícitos anticompetitivos, la existencia de mecanismos alternativos de distribución ha supuesto un incentivo al ya consolidado private enforcement anglosajón, es decir, la persecución por 
parte de privados para obtener montos restitutorios o indemnizatorios en su beneficio. En este contexto, el éxito de la acción no queda condicionada a la identificación de los afectados por un ilícito, lo que explica que en las acciones de clase del common law predomine el sistema optout, en virtud del cual la sentencia tendrá efectos respecto de todos los sujetos que pertenezcan a la clase afectada, salvo que hagan reserva de sus derechos.

Dentro de este panorama, algunos países latinoamericanos tienen la particularidad de haber introducido mecanismos similares a aquellos disponibles en el common law para distribuir montos indemnizatorios a sujetos indeterminados, aunque con distintos énfasis en cuanto a la discrecionalidad para determinar el fin de los montos obtenidos: mientras jurisdicciones como Brasil han buscado establecer una regulación que permita reparar de la mejor forma el bien jurídico afectado, México y Chile han establecido, de antemano, el fin al que irán a parar los montos indemnizatorios, lo que plantea el evidente reparo de que, en definitiva, no van a parar a los bolsillos de quienes sufrieron una disminución patrimonial. Estas innovaciones permiten cuestionarse, en primer lugar, la conveniencia de introducir estos mecanismos en países de derecho civil continental y, en segundo, los resguardos que deben adoptarse en caso de que, efectivamente, se incorporen.

La posibilidad de que una determinada atribución patrimonial pueda hacerse valer a pesar de tener por objeto a una persona indeterminada es un problema que excede, en cierto sentido, el ámbito de las acciones de clase y que ha sido abordado desde hace siglos a propósito de diversos problemas. En la esfera del common law anglosajón resulta particularmente relevante la llamada doctrina del cy-près, cuyo propósito original es redestinar el objeto de fundaciones que no pueden cumplir el propósito originalmente previsto por el instituyente. El mismo término usado para describir esta doctrina (cy-près) es alusivo de su forma de operar: en estos casos, el destino que se debe asignar a la atribución patrimonial debe ser "tan cercano como sea posible" (cy près comme possible, en francés normando medieval) al fin que originalmente buscaba quien realizó la disposición patrimonial (Suárez, 2017, p. 335), por lo que se da una importante libertad al juez para determinar su destino. Esta doctrina tuvo un enorme desarrollo jurisprudencial a través de los 
siglos y sería adaptada, en el siglo XX, para servir a las acciones de clase. Por su parte, el ius commune también conoció la posibilidad de redestinar el objeto de una liberalidad a fin de atender, de la mejor forma, el fin originalmente previsto por el instituyente. Sin embargo, a diferencia de lo ocurrido en el common law, no se concedió al juez libertad alguna en este punto. Asimismo, el ius commune elaboró una doctrina -lo que resulta especialmente relevante para efectos del presente trabajo- que permitía restituir lo cobrado en exceso a sujetos indeterminados; esta fue abandonada en las codificaciones modernas.

Este diverso punto de partida abre un abismo entre el derecho civil continental y el common law en materia de responsabilidad civil, lo que hace tanto más urgente determinar qué precauciones deben considerarse al introducir, de forma aislada, una de las manifestaciones de la doctrina del $c y$-près anglosajón en las acciones de clase latinoamericanas.

\section{Common law, la doctrina del cy-près y las acciones de clase}

\section{Orígenes históricos y alcance de la doctrina del cy-près}

La doctrina de cy-près encuentra ciertos antecedentes fuera del common law; en realidad, mucho antes de que dicho sistema legal comenzara a gestarse. Se suele entender que esta doctrina estaría en parte inspirada en las soluciones del derecho romano (Suárez, 2017), del Digesto de Justiniano $(33,2,16)$ que contiene textos que reconocían la necesidad de respetar la voluntad del instituyente de una liberalidad cuando no fuera posible llevarla a efecto en los términos dispuestos, redestinándola a un fin lo más cercano al originalmente contemplado. Esta solución sería, por lo demás, abundantemente recogida por diversos emperadores en época posclásica. Por ejemplo, Justiniano sancionó en su Codex $(1,3,49)$ la validez de las liberalidades efectuadas por causa de muerte en favor de colectivos indeterminados con fines caritativos, como sería el caso de alguien que dejase bienes para la redención de los cautivos o a los pobres. Esta regulación dispuso, asimismo, el fin que debe darse a este tipo de disposiciones patrimoniales. 
No se sabe con exactitud cómo dicha doctrina fue introducida en el derecho inglés, pero se cree que tiene que ver con las prácticas medievales de realizar donaciones por la salvación del alma y los eventuales problemas de asignación de aquellas donaciones a los fines que más se asemejaran a los deseos del donante (Fisch, 1953, p. 375). Se suelen fijar las primeras aplicaciones de esta doctrina también en la época medieval, en el contexto de la jurisdicción del Lord Chancellor que introdujo, en el contexto de la court of equity, la posibilidad de que un tribunal redestine el fin de una institución caritativa en caso de que surjan circunstancias que obstaculicen o impidan el fin originalmente pretendido (Suárez, 2017, p. 337).

Con la evolución del derecho inglés, la doctrina del cy-près quedó vinculada especialmente a los trusts y, específicamente, a los charitable trusts (Suárez, 2017). Esta doctrina se aplicó cuando los charitable trusts establecían como beneficiarios de cierto objeto o cantidad de dinero a una organización de caridad que luego no existía, cuando era imposible realizar aquella donación o cuando la misma se había vuelto contraria al orden público (Yale, 1939, p. 305). Frente a esos casos, las cortes ordenaban satisfacer los deseos del donante al entregar los bienes al segundo mejor destino que cumpliera as nearly as posible los deseos originales del fideicomitente (Boies \& Keith, 2014, p. 269). Esta concepción de la doctrina del cy-près se encuentra actualmente presente en las acciones de clase en el marco de la protección de los derechos de los consumidores. Así, el objetivo de los cy-près trust funds es conseguir, por vía indirecta, una reparación tan cercana como sea posible a los miembros de la clase, como se verá. El desarrollo del cy-près en el derecho inglés siguió ligado sobre todo a los trusts y así, en la actualidad, esta doctrina no se asocia en aquel país a la compensación a sujetos indeterminados, o al menos no de forma relevante.

Dicha concepción, en cambio, sí se encuentra presente en el derecho estadounidense. En un principio. la doctrina de cy-près, siguiendo al derecho inglés, llegó a Estados Unidos de la mano de la regulación de los trusts (Rodheim, 2017, p. 1102). Sin embargo, en 1996, una reforma del Federal Rules Advisory Committee a la Federal Rule of Civil Procedure 23 -regla de procedimiento que permite la unión de acciones en el derecho estadounidense-marcó el inició de la aplicación de cy-près en materia de 
acciones de clase. Dicho cambio permitió la inclusión de miembros de una clase ausentes en acciones de clase obligatoria. Como consecuencia lógica de dicha modificación, luego de una acción de clase exitosa quedaban montos importantes de dinero que no eran reclamados y que pertenecían a aquellos sujetos indeterminados que, finalmente, nunca los solicitaban. La necesidad de encontrar la forma de repartir aquellos fondos de alguna manera, considerando que identificar a los consumidores indeterminados era no solo muy difícil sino además muy costoso, fue lo que eventualmente trajo la doctrina del cy-près a las acciones de clase en Estados Unidos (Chasin, 2015, p. 1468).

\section{Cy-près y acciones colectivas}

La indemnización de consumidores indeterminados, especialmente en el contexto de ilícitos anticompetitivos, enfrentó una resistencia inicial en Estados Unidos debido a la negación de legitimación activa a los compradores indirectos (indirect purchasers) para reclamar los perjuicios que hubieran experimentado. Permitir la indemnización en este caso, se argumentaba, implicaba un nivel demasiado elevado de incertidumbre. A mediados del siglo XX, Posner (1969, p. 1590) afirmaba que las acciones de clase para reclamar perjuicios eran una ilusión, al no existir un método factible para identificar y reembolsar al consumidor que pudo haber pagado mucho por una escobilla de dientes hace algunos años como consecuencia de una colusión de precios de los fabricantes del producto. El problema se agravaba especialmente debido a la dificultad que implica distinguir qué parte del daño fue traspasado a los consumidores finales, lo que limitó la legitimación activa a los compradores directos (fueran intermediarios o consumidores) que reclamaran perjuicios por ilícitos anticompetitivos. Sin embargo, esta regla federal fue superada gradualmente por los distintos estados al permitirse incluso, de forma general, que los compradores indirectos soliciten perjuicios (Fuchs \& Vives, 2015).

Frente al problema de indemnizar a un grupo indeterminado de consumidores, el common law ha ofrecido diversas alternativas, catalogadas por lo general como supuestos de fluid recovery (Tolosa, 2017, pp. 79-80). Un primer mecanismo, hasta cierto punto intuitivo, es que se compense a los consumidores que debieron pagar un sobreprecio con una reducción 
de precios, de modo que paguen menos por productos por los que antes pagaron de más. Sin embargo, la desventaja más evidente que presenta esta modalidad se refiere a las distorsiones que introduce en el mercado por cuanto pone en una situación comprometedora a los competidores que deben continuar vendiendo al precio habitual (Howells, 2011, pp. 60-61; Tolosa, 2017, pp. 87-89). Adicionalmente, en relación a la clase afectada, la existencia de menores precios atraería a sujetos que no fueron afectados originalmente, por lo que existiría el riesgo, por una parte, de compensar en menor medida a los afectados y, por otra, de ofrecer compensaciones a quienes no experimentaron pérdidas.

Un mecanismo similar, que incluso puede considerarse una forma de implementación de la modalidad anterior, consiste en entregar $\mathrm{cu}^{-}$ pones entre los consumidores afectados (Tolosa, 2017, pp. 81-82). Esta modalidad tiene los mismos inconvenientes que la anterior que se suman a las complicaciones que envuelve el uso de cupones - tales como su vencimiento- lo que, en definitiva, lleva a que solo una fracción sea eventualmente utilizada. Hay estudios que señalan que solo el 15\% de los cupones se canjea (Howells, 2011, p. 61). Por todo lo anterior, el uso de cupones como mecanismo de compensación ha sido blanco de críticas y hay quienes han señalado que, si los cupones son un medio de pago tan conveniente, debería pagarse a los abogados con ellos (Howells, 2011, p. 61).

El formato más común de fluid recovery utilizado en Estados Unidos para indemnizar a consumidores indeterminados implica recurrir a los llamados cy-près trust funds, es decir, fondos destinados a cumplir diversos fines que vayan en beneficio de los consumidores afectados. Este mecanismo opera en la práctica de forma residual a la atribución directa de fondos a consumidores que debe ser preferida de ser posible, lo que implica, a su vez, acreditar la calidad de miembro del grupo (Tolosa, 2017, p. 85).

Shepherd fue uno de los primeros autores en sugerir la aplicación de cy-près para solucionar el problema de los fondos no repartidos al analizar (en 1972) esta problemática y al explicar de forma clara que las alternativas eran básicamente dos: o se eliminaba la causa del problema - por ejemplo, delimitando mejor las clases o, eventualmente, eliminando las compensaciones a consumidores indeterminados- o se buscaba una forma de repartir el dinero no reclamado (1972, p. 449). La concreción 
de la segunda alternativa llevó a este autor a proponer la aplicación de cy-près, en los siguientes términos:

When distribution problems arise in large class actions, courts may seek to apply their own version of cy pres by effectuating as closely as possible the intent of the legislature in providing the legal remedies on which the main cause of action was based. (Sheperd, 1972, p. 452)

Al poco tiempo aparece el primer fallo de un tribunal que aplica esta doctrina. La precursora fue la Corte de Distrito del Distrito Sur de Nueva York, al fallar Miller v. Steinbach (268 F. Supp. 255 [S.D.N.Y. 1974]), donde accionistas de cuatro millones de acciones de una compañía que se había fusionado con otra reclamaban por los términos en que aquello se había llevado a cabo. Como explica Gentle, el acuerdo conciliatorio que se alcanzó fue modesto y no podía repartirse de forma realista entre los accionistas, por lo que se le dio un uso alternativo a ese dinero (2015, pp. 2-3). Posteriormente, esta doctrina vio su aplicación en materia de compensación a consumidores afectados por ilícitos de competencia. Por ejemplo, en In re Compact Disc Minimum Advertised Price Antitrust Litigation, un caso de fijación de precios de la industria musical, el juez consultó con las partes el mejor destino para US\$271.000 que no habían sido cobrados al destinarlos, en parte, a programas de digitalización de música - para que los afectados pudieran acceder a contenido musical en línea-y en parte a programas de educación musical -que eventualmente podrían traducirse en producciones musicales que los afectados pudieran disfrutar- (Chasin, 2015, p. 1479).

\section{Desafios y críticas del cy-près}

Los cy-près awards no han estado libres de críticas, especialmente porque a veces no es claro que los afectados reciban un beneficio siquiera indirecto, por lo que a veces se pierde toda función reparatoria. Esto se agrava en particular en Estados Unidos debido a la gran discrecionalidad que tiene el juez en este punto, pues permite que este se convierta en un generoso filántropo al elegir la destinación de los fondos de compensación (Chasin, 2015, pp. 1470-1473). Por ejemplo, ha habido casos 
en los que, con el objeto de reparar a los consumidores afectados por ilícitos anticompetitivos, el juez de turno ha decidido que importantes cantidades vayan a beneficio de su alma mater para financiar estudios sobre libre competencia, por lo que queda en un segundo plano una auténtica compensación a los consumidores. Algunos autores han señalado incluso que este sistema tiene una sorprendente falta de estándares que se hacen cumplir judicialmente (Sheil, 2015, p. 945). En consecuencia, la doctrina ha hecho un llamado a terminar con la arbitrariedad mediante la generación de instancias más participativas a la hora de determinar la destinación de los fondos, lo que, se alega, podría lograrse de forma general al involucrar a aquellos miembros de la clase que sí estén identificados para consultarles respecto al mejor mecanismo para compensar a los afectados (Chasin, 2015, pp. 1487-1495).

En este contexto de crítica, en abril de 2018, la Corte Suprema de Estados Unidos decidió por primera vez revisar un fallo de un tribunal inferior para examinar si un acuerdo conciliatorio que entrega compensaciones cy-près, pero no entrega ninguna compensación directa a la clase de consumidores afectada, es "justo, razonable y adecuado" (fair, resonable, and adequate), que es el estándar que fija la referida Regla 23 de las Reglas federales de procedimiento de Estados Unidos para que un tribunal pueda aprobar un acuerdo conciliatorio en el marco de las acciones de clase de consumidores (Fed. R. Civ. P. § IV 12(e)(2)). El caso que se revisará, Frank v. Gaos, comenzó en la Corte de Distrito del Distrito del Norte de California por supuestas violaciones por parte de Google a la privacidad de sus usuarios. Las partes que interpusieron la acción alcanzaron un acuerdo con dicha empresa, que fue luego aprobado por la Corte de Distrito (In re Google Referrer Header Privacy Litigation, 87 F.Supp.3d 1122 (N.D. Cal., 2015)), pero quienes se oponían al acuerdo apelaron. La Corte de Apelaciones de Estados Unidos para el Noveno Circuito reconoció que el acuerdo "involves a cy-près-only distribution of the \$5.3 million or so" (In Re Google Referrer Header Privacy Litigation, 869 F.3d 737 (9th Cir. 2017), p. 7), y eventualmente consideró que el fallo que revisaba era correcto. Los objetores del acuerdo continuaron con su pretensión y solicitaron que la Corte Suprema de Estados Unidos revisara la doctrina que aplicaba en el fallo, petición que fue concedida el 30 de abril de 2018. 
La decisión de la Corte Suprema de Estados Unidos de revisar por primera vez este tema trae de nuevo a la mesa la discusión sobre la aplicación de esta doctrina y, específicamente, pone en tela de juicio la indemnización a consumidores mediante cy-près awards y el fin que estaría detrás de una compensación de este tipo, como veremos también a continuación. El certiorari del tribunal máximo de Estados Unidos, en este caso, ha recordado la declaración del presidente de aquella Corte Suprema, John Robert, quien en 2013 estuvo de acuerdo con la decisión de la mayoría de denegar un certiorari en un caso también de cy-près settlement porque la revisión de aquel caso

might not have afforded the Court an opportunity to address more fundamental concerns surrounding the use of such remedies in class action litigation, including when, if ever, such relief should be considered; how to assess its fairness as a general matter; whether new entities may be established as part of such relief; if not, how existing entities should be selected; what the respective roles of the judge and parties are in shaping a cy pres remedy; how closely the goals of any enlisted organization must correspond to the interests of the class; and so on. This Court has not previously addressed any of these issues (Statement of Roberts, C. J., Megan Marek v. Sean Lane, 571 U. S., 2013, p. 4).

En esta declaración, Roberts ya advertía sobre los riesgos que implicaba entregar compensaciones de acuerdo a la doctrina cy-près. Llama la atención que incluso en Estados Unidos, que tiene un derecho que en materia de responsabilidad civil responde a principios distintos que los que rigen en el derecho civil continental, se identifiquen problemas de equidad en la aplicación de cy-près para repartir las indemnizaciones a consumidores. Volveremos sobre este punto, pero desde ya podemos advertir que los problemas son aún mayores en ordenamientos en que los principios de certidumbre y personalidad del daño priman en esta materia.

Un segundo desafío de esta doctrina, relacionado de cerca con el anterior, es la identificación de la función que cumplen las compensaciones cy-près a consumidores. El sistema de acciones de clase de Estados Unidos comparte con algunos ordenamientos latinoamericanos -específicamente Brasil, en parte México, y recientemente Chile- la posibilidad de demandar en beneficio de una clase indeterminada e independiente 
de la ulterior posibilidad de identificar a sus miembros. La gran diferencia entre el primero y los segundos sistemas es que el sistema de la responsabilidad civil estadounidense responde a principios distintos a los que se aplican en países de tradición civil continental, por lo que el problema de la indeterminación de los afectados ha generado menores reparos. De todas formas, hay una clara preferencia en países del common law por privilegiar formas de determinación de los afectados al recurrir solo, de forma supletoria, a modalidades de indemnización de consumidores indeterminados. En Estados Unidos, por ejemplo, es común que se condene a un proveedor a una cifra general que comprenda el daño causado a toda la clase y que, con posterioridad, aparezcan distintos sitios web en los que se llama a los miembros de la clase a acreditar su condición de tales llenando un formulario y presentando distintos antecedentes. Está de más decir que dichos llamados no suelen generar demasiada adhesión, si se consideran las complejidades que implica acreditar la pertenencia a la clase y los discretos montos que suelen repartirse entre los consumidores. El problema luego es qué hacer con los fondos que no se reclaman. Así, el problema de la compensación de consumidores indeterminados tiene un cierto carácter residual. Sin embargo, cabe destacar que, en ciertos casos, se privilegian modalidades alternativas de compensación aun cuando los consumidores afectados sean determinables, como se vio antes.

De todas formas, la doctrina se divide sobre la función exacta de los cy près trust funds ya que, mientras algunos autores se inclinan por enfatizar su función compensatoria, otros destacan que cumplen más bien una función disuasoria y que, en el mejor de los casos, se relacionan con una forma de justicia distributiva. Como se ha referido anteriormente, la aplicación de la doctrina del cy-près a las acciones de clase tiene solo unas décadas de antigüedad y supuso extender una doctrina concebida para la constitución de fundaciones a un problema enteramente diverso. Por lo mismo, no es de extrañar que, mientras algunos autores se inclinan por enfatizar su función compensatoria, otros destacan que cumplen más bien una función disuasoria y que, en el mejor de los casos, se relacionan con una forma de justicia distributiva (Howells, 2011, pp. 56-60, 64), por lo que la adecuada compensación de cada uno de los afectados a menudo queda en un segundo plano. Finalmente, cabe notar que no en todos los países del common law se acepta en igual medida el recurso a los cy-près 
trust funds; por ejemplo, en Australia, existe una fuerte resistencia pues se ha alegado que el desembolso económico en este caso parece constituirse más en una sanción que en una auténtica indemnización y que existiría, en cualquier caso, un riesgo importante de sobrecompensación (Howells, 2011, pp. 62-63).

\section{Certidumbre y opt-in: las acciones de clase del derecho civil continental}

\section{Ius commune $y$ atribuciones patrimoniales con sujeto indeterminado}

Si bien la posibilidad de conceder un monto indemnizatorio en favor de sujetos indeterminados parece ser un producto reciente del common law por medio de la adaptación de la doctrina del cy-près, lo cierto es que el ius commune desarrolló figuras similares. Desde luego, bajo la influencia del derecho romano, se admitió una cuota importante de indeterminación en los beneficiarios de liberalidades al permitir, por ejemplo, las disposiciones "en favor del alma" del testador y dar, en consecuencia, cierta libertad al juez o a diversas autoridades civiles o eclesiásticas para determinar el fin adecuado a dichas asignaciones. Sin embargo, para efectos del presente trabajo, resulta aún más pertinente el desarrollo de una serie de soluciones bajo la doctrina de la restitución (restitutio) que encuentra sus orígenes en el derecho canónico y prescribe de forma general que todo aquel que obtuviera algo de forma ilícita debía realizar una restitución en favor del afectado (Nufer, 1969; Hallebeek, 1996). En principio, esta doctrina se refería ante todo al fuero interno (forum internum) y se trataba, por lo tanto, de un problema fundamentalmente teológico-moral. En este sentido, Agustín de Hipona señalaba que no podía haber perdón de los pecados si no se realizaba la restitución, idea que fue recibida en el derecho canónico clásico por el Decreto de Graciano (C. 14 q. 6 c. 1, Augustinus ad Macedonium epist. 54) y el Liber Sextus (De regulis iuris, 6) lo que, a su turno, llevó a su análisis en sede jurídica, aunque siempre subsistió una cierta área difusa respecto a la distinción entre justicia terrenal (forum externum) y obligación moral (forum internum). 
Ya en la doctrina de Agustín de Hipona se destacaba que solo se estaba obligado a restituir si ello era posible, problema que sería abordado por la doctrina posterior. Tomás de Aquino desarrolló en detalle la doctrina de la restitución en su Suma Teológica (1894, II II q. 62 artículo 5), donde se plantea de forma general la pregunta, “AAcaso debe siempre restituirse a aquel de quien se toma una cosa?". Entre los argumentos para negarlo señala que nadie está obligado a lo imposible y que, a veces, es imposible realizar la restitución, como sucede cuando aquel de quien se tomó ha muerto o es desconocido. Responde luego a esta objeción al señalar que si aquel a quien debe restituirse es totalmente desconocido -aun después de una averiguación diligente- se puede restituir en la forma que se pueda, como dando limosnas para la salvación de esa persona, con lo que concluye "por lo tanto, no siempre se debe hacer la restitución a aquel de quien se tomó" (1894, II II q. 62 artículo 5). De esta forma, al ser imposible determinar al beneficiario, dar limosnas o realizar otros actos de caridad para su salvación parecería ser la única forma de compensarlo tras lo que queda la determinación en manos de la divinidad. Cabe destacar que Tomás de Aquino considera que la restitución es una forma de justicia conmutativa, no de forma distributiva, por lo que el desembolso para obras pías en favor del alma del beneficiario se entiende que conlleva un beneficio directo para este último.

La neoescolástica española y la escuela del derecho natural debatieron sobre la posibilidad y la forma de restituir a sujetos indeterminados (Nufer, 1969, p. 47). Quienes admitían la restitución en estos términos discutían cuál debía ser el destino exacto de la atribución patrimonial que consistía, normalmente, en obras pías destinadas al alma del beneficiario.

La doctrina de la restitución tuvo interesantes consecuencias en el contexto de los "monopolios", término que durante siglos describió genéricamente tanto el monopolio propiamente dicho como diversas formas de colusión (De Roover, 1951, p. 499). En el derecho romano, estas conductas se regulaban en un contexto esencialmente penal ya que su comisión podía acarrear penas tales como la confiscación de bienes o el destierro. Por lo mismo, no existe un análisis particular en Roma sobre las indemnizaciones procedentes a partir de un monopolio. Sin embargo, la figura del monopolio se analizó gradualmente también bajo el problema general del justo precio en tiempos de la segunda escolástica, 
por cuanto se entendió que la instauración de un monopolio implicaría el cobro de un precio superior al corriente. En este contexto, los autores de la escolástica española enmarcaron el análisis de los monopolios dentro de la doctrina de la restitución, entendiendo que el monopolista estaba obligado a restituir el sobreprecio cobrado a los consumidores (De Roover, 1952, p. 498). Si se consideran las peculiaridades de esta situación, inevitablemente surgirá la pregunta sobre cómo compensar a los sujetos afectados cuando resultan desconocidos. Si bien la mayoría de los autores no se pronuncia expresamente sobre el punto, es un lugar común en la doctrina de los siglos XVI y XVII que los monopolistas debían restituir a los consumidores el sobreprecio pagado, como se aprecia en los escritos de De Molina (1659, tract. II, disp. 345, §§ 5), Lessius (1610, lib. 2, cap. 21, dub. 20) y Grocio (1631, libro II, cap. 16). De todas formas, algunos autores prescriben fórmulas específicas al efecto, al establecer, por ejemplo, la obligación de vender al público a un precio menor (Concina, 1770, p. 32).

Este panorama podría sugerir que el ius commune prefiguró en varios siglos a la aplicación de mecanismos de fluid recovery. Sin embargo, las doctrinas que permitían encontrar un destino a atribuciones patrimoniales referidas a sujetos indeterminados fueron paulatinamente abandonadas. Por ejemplo, mientras las antiguas disposiciones que permitían redestinar el objeto de una liberalidad dejada a sujetos indeterminados recibieron un abundante desarrollo jurisprudencial en el common law, bajo la doctrina del cy-près, los sistemas de derecho civil continental consolidaron una regulación mucho menos exuberante. Así, el Código Civil de Andrés Bello (Código Civil chileno, Artículo 1 056; Código Civil colombiano, Artículo 1113) establece que las asignaciones al alma del testador o a un establecimiento de beneficencia sin designar, se darán al establecimiento que designe el presidente de la República (el "jefe del territorio" en la actual redacción del Código Civil colombiano) y, actualmente, por ejemplo en Chile, van a parar sin más al Fondo Nacional de Salud (Salinas, 2005) sin que exista margen para que el juez busque un fin más adecuado a la intención del testador.

De forma similar, las ideas de la escolástica, en materia de restitución a sujetos indeterminados, perdieron fuerza entre los siglos XVIII y XIX cuando las teorías económicas de la escolástica fueron en gran parte 
abandonadas. Al mismo tiempo, esta doctrina se hizo superflua para atender, por ejemplo, a la represión de los monopolios, materia que fue regulada, siguiendo una antigua tradición, desde el punto de vista del derecho penal (Cuerdo \& Sánchez, 2014) y, posteriormente, con base en el contencioso administrativo donde perdió, en principio, toda relevancia la indemnización de los sujetos afectados por la conducta sancionada, al menos en el derecho civil continental. Por otra parte, en materia de responsabilidad civil, se consolidaría la idea de que el daño debe ser personal y cierto, al indemnizar específicamente a la persona que sufrió el daño por el monto del perjuicio verdaderamente sufrido, todo lo cual excluye la posibilidad de obtener una indemnización o restitución en beneficio de sujetos indeterminados.

\section{Public enforcement y certidumbre para indemnizar en los sistemas de derecho civil continental}

En el contexto descrito en el apartado anterior, el desarrollo de mecanismos generales para indemnizar a sujetos indeterminados no ha sido en caso alguno una prioridad en jurisdicciones europeas de derecho civil continental que se han concentrado, ante todo, en la aplicación de multas. En la Unión Europea, por ejemplo, en la determinación de multas por ilícitos anticompetitivos se atiende, entre otros factores, al beneficio obtenido y al daño causado al mercado por lo que el infractor, en último término, tendrá que asumir el costo de los daños causados en la forma de una multa a beneficio fiscal. En este contexto no resulta necesario conceder una indemnización a fin de obtener un fin disuasivo. Por lo mismo, la normativa europea sobre daños por ilícitos anticompetitivos no aboga por la introducción de procedimientos colectivos para pedir la indemnización de perjuicios (Directiva 104 UE del Parlamento Europeo, 2014, considerando 13).

Frente al papel preponderante del public enforcement, se mantiene un respeto en los ordenamientos jurídicos europeos por los principios de personalidad y de certeza del daño en materia de responsabilidad civil; se excluye, de forma absoluta, la indemnización a consumidores indeterminados en el contexto de procedimientos colectivos. Ello, por cuanto todos los ordenamientos jurídicos europeos de derecho civil continental 
que establecen acciones colectivas lo hacen mediante la modalidad opt-in, en virtud de la cual solo quienes hayan acudido al juicio y hayan acreditado su calidad de miembros del grupo afectado podrán exigir una indemnización (Howells, 2011, pp. 65-66). De hecho, la Recomendación 2013/396/UE de la Comisión Europea sugiere a los Estados miembro establecer sistemas de participación voluntaria o opt-in antes que sistemas opt-out (Recomendación 2013/396/UE de la Comisión Europea), precisamente por críticas que se le hacen a estos últimos sistemas desde la óptica del derecho civil continental (Sande, 2018, pp. 236-237). Este es por ejemplo el caso de Francia que introdujo recientemente una ley que regula los procedimientos colectivos en materia de consumidor al establecer un procedimiento de publicidad para que todos los afectados que lo deseen se sumen al procedimiento (Código de Consumo francés, Artículo L423-5). Lo mismo ocurre en España, donde la Ley de Enjuiciamiento Civil prevé disposiciones para la suspensión de acciones colectivas con afectados indeterminados mientras se publicita la demanda para que se adhieran otros perjudicados (Artículo 15.3).

Algunas jurisdicciones europeas han sido aún más exigentes al excluir de plano la posibilidad de solicitar indemnizaciones en el marco de procedimientos colectivos. Jurisdicciones con una regulación altamente sofisticada ofrecen soluciones de este tipo, como es el caso de Austria, donde no existen normas generales sobre procedimientos colectivos lo que dio lugar, en su momento, a las llamadas acciones de clase "estilo austriaco": a falta de una regulación especial, los consumidores afectados por ilícitos anticompetitivos pueden ceder su pretensión a una entidad que vela por los derechos de los consumidores a fin de que esta última los haga valer conjuntamente ante tribunales (Elsner, Zadler \& Kos, 2016, p. 54). La misma solución se encuentra disponible en Alemania (Dietrich E Hartmann-Rüppel, 2013, p. 206). En Holanda sí existe una regulación general sobre procedimientos colectivos, pero el Código Civil holandés excluye tajantemente la pretensión indemnizatoria de los procedimientos colectivos (Código Civil holandés, libro 3, Artículo 305a). Esto no trae consigo la indefensión de los consumidores que pueden ceder su derecho litigioso a una entidad jurídica que recurre a una follow-on action para pedir la indemnización de perjuicios (Bosch, 2016, p. 265). Algunos países que recurrían en la práctica a mecanismos similares, como era el 
caso de Francia, lo abandonaron ante los pobres resultados en términos del número de sujetos afectados que se hacían parte en el juicio (Howells, 2011, pp. 58-59).

En virtud de lo anterior, resulta manifiesto que la posibilidad de indemnizar a consumidores indeterminados se excluye de plano en los sistemas de derecho civil continental europeos, sea que cuenten con una regulación especial sobre acciones colectivas o no, tanto por el papel preponderante que se otorga a la multa a la hora de disuadir, como por el respeto a los principios generales de la responsabilidad civil. Cabe observar, en este punto, que una de las principales motivaciones en Europa por instaurar sistemas de compensación con modalidad opt-in ha sido evitar la experiencia de Estados Unidos que se percibe a menudo como negativa por dar pie a abusos en la litigación.

\section{¿Cy-près en las acciones de clase latinoamericanas?}

Si bien la mayoría de los sistemas de derecho civil continental excluyen cualquier forma de compensación en beneficio de sujetos indeterminados, esta regla se rompe en el caso de Brasil. Al estar permitida, de forma general, la posibilidad de demandar en beneficio de consumidores indeterminados, se contempla la eventualidad de que quede un monto sin reclamar luego de un periodo determinado que se destinará a diversos fondos establecidos por ley (Ley 7.347 de 1985, Artículo 13; Código de Defensa del Consumidor de Brasil, Artículo 100); existe una discrecionalidad relevante por parte de la autoridad para destinarlos de la mejor forma para atender el bien jurídico vulnerado (Gidi, 2004, pp. 38-39).

En 2004, el Instituto Iberoamericano de Derecho Procesal aprobó el Código Modelo de Procesos Colectivos para Iberoamérica tras identificar, precisamente, que los derechos colectivos de los consumidores se encontraban muchas veces desprotegidos en los ordenamientos iberoamericanos. Dicho código establece que las sentencias que acojan las pretensiones de los actores que interpongan acciones colectivas podrán declarar de forma genérica el daño que los consumidores han sufrido y condenar al demandado a indemnizar a todas las víctimas existentes, aun cuando estas no se encuentren identificadas (Capítulo IV). 
El Artículo 27 establece, de forma similar a la regulación brasilera, que luego de un año sin que concurran interesados en número representativo, podrá promoverse la liquidación y ejecución colectiva. Ello, a su turno, permite destinar el monto obtenido al Fondo de los Derechos Difusos e Individuales Homogéneos, regulado en el Artículo $8^{\circ}$, en el que deberían participar diversos miembros de la administración, el poder judicial y la comunidad con el fin de destinar, de la mejor forma, los montos obtenidos a reconstituir los bienes lesionados o beneficiar de otra forma el bien jurídico perjudicado.

Estas directrices no se han atendido debidamente en recientes reformas latinoamericanas. En 2011, México realizó una importante reforma tendiente a proteger los intereses difusos de los consumidores al incorporar modificaciones, entre otras, al Código Federal de Procedimientos Civiles, al crear un nuevo libro titulado "De las acciones colectivas", en parte inspirado en la experiencia brasilera. Si bien se autoriza la indemnización de perjuicios a sujetos indeterminados, al formar un fondo que recibirá los recursos no reclamados que provengan de las sentencias fruto de colectivas difusas (Artículo 624), se establece una regulación restrictiva sobre el uso de los montos obtenidos (Artículo 625) que impide atribuirlos a fines distintos a los gastos derivados de los procesos colectivos, honorarios de la parte demandante o gastos judiciales. De esta forma, si bien esta regulación parece inspirada en la brasilera, su técnica legislativa y su aplicación práctica han recibido fuerte crítica en doctrina y autoridades mexicanas (Elizalde \& Morales, 2018, pp. 43-44). Por nuestra parte, cabe advertir que con esta regulación el legislador fija de antemano el destino de los fondos, lo que hace especialmente cuestionable que se cumpla efectivamente una función resarcitoria. Ello implica que la reparación de consumidores indeterminados se asemeja a una segunda multa que el infractor debe pagar, pero cuyo destino se asigna a fondos determinados en lugar de ir a parar de forma genérica al erario.

La regulación descrita en el párrafo precedente encuentra similitudes con la reciente reforma operada en Chile a la Ley de Protección de los Derechos del Consumidor. Originalmente, la Ley 19.955, que introdujo las acciones colectivas en Chile (limitadas al derecho del consumidor), estableció un estricto criterio de determinación de los afectados para dar lugar a la indemnización de perjuicios, exigiendo la prueba del vínculo 
contractual entre el infractor y los consumidores afectados. De esta forma, se excluía la indemnización del llamado interés difuso que se refiere (en la terminología de derecho del consumo chileno) a sujetos indeterminados. Cabe destacar que esta limitación se introdujo deliberadamente para evitar la utilización abusiva de las acciones de clase de la ley del consumidor (Historia de la Ley 19.955, 2004, pp. 163 y 413).

La situación descrita cambia drásticamente con la reciente promulgación de la Ley 21.081 que permite demandar perjuicios en casos de interés difuso, es decir, donde los afectados sean sujetos indeterminados. En concordancia con este cambio, se establece (en las hipótesis específicas del nuevo Artículo 53 B y 53 C) un destino para los montos no cobrados, es decir, un fondo especial contemplado en el Artículo 11 bis de la Ley 19.496 para financiar las asociaciones de consumidores.

Las regulaciones presentadas, en cuanto permiten demandar en favor de sujetos indeterminados y en definitiva destinar parte de lo obtenido a un fin que no es directamente reparatorio, llevan a cuestionarse su adecuación a los principios de personalidad y certeza propios de la responsabilidad civil, como ha planteado Barrientos (2017, p. 22) a propósito de la reforma en Chile. Para responder esta pregunta, cabe diferenciar el caso de Brasil de la regulación de México y Chile ya que, en estos últimos dos casos, la ausencia de una función indemnizatoria en esta adaptación del cy-près en las acciones de clase latinoamericanas resulta aún más evidente si se considera que se aparta de forma relevante de los estándares mínimos establecidos en el propio common law. Como vimos anteriormente, en la esencia del cy-près está buscar un fin lo más próximo posible al original lo que, en materia de acciones de clase, implica dar un margen de libertad al juez para encontrar un destino a los montos indemnizatorios que beneficie (aunque sea indirectamente) de la mejor forma a los miembros de la clase, aun cuando a menudo se haya abusado de esta discrecionalidad. De manera muy diferente, en las versiones mexicana y chilena del cy-près, se ha renunciado de antemano a buscar una reparación o indemnización - aun indirecta- de los miembros de la clase y dichos montos van a parar a fondos fijados por ley lo que, si bien puede ser eficiente en términos de costos (Tolosa, 2017, pp. 90-91), no contribuye en nada a una auténtica reparación. 
Otra crítica que cabe realizar a las actuales adaptaciones mexicana y chilena del cy-près es que pierden de vista el fin residual que esta institución cumple en los países del common law. Como queda visto, dichas jurisdicciones aplican los cy-près awards únicamente para los montos residuales que no sean reclamados, y se da privilegio a que la mayor parte de la restitución o indemnización vaya a manos de miembros de la clase. Contrario a este principio, las normas antedichas favorecen que los montos obtenidos fruto de una demanda exitosa a favor de consumidores indeterminados vayan a parar en bloque a los fondos establecidos por ley. Este es sobre todo el caso en Chile, donde la reciente reforma mantiene un sistema de opt-out para efectos de declarar la indemnización (Artículo 54 de la Ley 19.496), pero exige un estricto sistema de optin para cobrarla (Artículo 54 C, 54 D y 54 E de la ley 19.496), lo que implica en la práctica que, con el texto reformado, podrán establecerse grandes sumas indemnizatorias en favor de sujetos indeterminados que, rara vez, contarán con los medios para acreditar su condición a la clase afectada, por lo que los montos conseguidos irán a parar directamente a los fondos establecidos por ley. En estas condiciones, nada parece más conveniente para una asociación de consumidores, a fin de mantener una fuente de ingresos estable, que buscar la representación de grupos donde los consumidores permanezcan indeterminados.

Dejando de lado las peculiares deficiencias de la normativa chilena y mexicana, cabe preguntarse, de forma general, si la doctrina del cy-près tiene cabida en las acciones de clase de jurisdicciones de derecho civil continental y si, acaso, un sistema como el brasilero no resultaría, en términos generales, aceptable. Cabe destacar que autores como Tolosa (2017) se han mostrado partidarios de los mecanismos de fluid recovery a fin de que el demandado internalice el valor de los daños causados al promover un diseño que privilegie minimizar los costos sociales de implementación aun a costo de privilegiar la función disuasiva por sobre la indemnizatoria.

Pese a esta defensa de una incorporación latinoamericana del cy-près, creemos importante no desatender el ejemplo de las jurisdicciones europeas de derecho civil continental que no han renunciado a los principios básicos de la responsabilidad civil para dar lugar a indemnizaciones en el contexto de las acciones de clase, proscribiendo la indemnización de 
sujetos indeterminados y dejando el fin disuasivo exclusivamente en manos de las sanciones infraccionales. Al efecto, la evolución histórica comparada, anteriormente descrita, resulta en especial ilustrativa: por una parte, el common law extendió la doctrina del cy-près a las acciones de clase en el contexto del predominio de un private enforcement inspirado, por lo demás, en principios de responsabilidad civil ajenos al derecho civil continental; por otra parte, este último sistema jurídico abandonó hace siglos las modalidades de restitución o indemnización en favor de sujetos indeterminados al realzar la importancia de las multas para alcanzar fines disuasivos respecto de conductas que afectan a un grupo extendido de personas bajo un esquema de public enforcement en el que los principios tradicionales de la responsabilidad civil conservan su vigencia, por lo que los montos que se obtengan en favor de privados deben cumplir, ante todo, un fin reparatorio.

A diferencia del modelo europeo, la adaptación del cy-près en Latinoamérica propende, en mayor o menor medida (mayor en Chile, menor en Brasil) a un fin eminentemente disuasorio que busca, a toda costa, que el infractor internalice los mayores costos derivados de su actuar pero renuncie en el proceso, al menos parcialmente, a una auténtica función indemnizatoria y contraría la lógica y la función propia de la responsabilidad civil vigente en la mayor parte de los países latinoamericanos. En este contexto parece conveniente seguir la experiencia europea al buscar que la multa cumpla un fin disuasivo, obligando al infractor a internalizar el daño causado, al tiempo que se respeten el fin indemnizatorio de la responsabilidad civil y los principios que la gobiernan. Para el legislador esto implica establecer multas que satisfagan un fin disuasivo, reservando a la responsabilidad civil un fin reparatorio, por lo que debe atender con cuidado a la necesidad de incorporar los cy-près awards en las acciones de clase y, en caso de admitirlos, velar porque se cumpla de la mejor forma el fin indemnizatorio por medio de la adopción de algunos de los resguardos planteados en el common law. En este sentido, las complicaciones asociadas a la indemnización a sujetos indeterminados no deberían canalizarse por medio de la flexibilización y la distorsión de los principios de la responsabilidad civil a fin de privar al infractor de un provecho ilícito, sino que dicha función disuasoria debería quedar entregada, sin más, a la multa que se aplique frente a una conducta ilegal. Para el juzgador, 
esta conclusión implica un llamado a proceder con cuidado al conceder indemnizaciones que no irán a parar al bolsillo de los afectados, precisamente porque no se consigue con ello fin reparatorio alguno.

\section{Conclusiones}

El panorama ofrecido en el presente trabajo permite delinear una serie de matices en torno a la conveniencia de la restitución o indemnización a sujetos indeterminados. Si bien dicha posibilidad se ha reconocido en el common law como extensión de la doctrina del cy-près, se ha llevado a cabo con importantes resguardos al buscar, ante todo, que los montos obtenidos se distribuyan directamente entre los afectados y que solo de forma residual se asignen los no distribuidos a un fin alternativo que los beneficie de la mejor manera.

El derecho civil continental, por otra parte, ha sido mucho más estricto en materia de determinación de los beneficiarios de una restitución o indemnización al abandonar, por ejemplo, las antiguas doctrinas que permitían restituir montos obtenidos ilícitamente por medio de atribuciones patrimoniales en favor del alma del afectado. En lugar de ello, la responsabilidad civil se ha construido sobre la necesidad de determinar con certeza el daño y la persona que debe ser reparada, y reservar a la multa una finalidad estrictamente disuasiva. Algunas jurisdicciones latinoamericanas se han apartado de este trazado al permitir la procedencia de demandar una indemnización de perjuicios en favor de sujetos indeterminados lo que implica - en mayor o menor medida, según la jurisdicción - una renuncia a una función estrictamente indemnizatoria de la responsabilidad civil.

Con base en las consideraciones anteriormente expuestas, resulta cuestionable la conveniencia de introducir la posibilidad de exigir una indemnización a favor de sujetos indeterminados. Si lo que se busca es conseguir un efecto disuasivo frente a la comisión de ilícitos determinados, dicho fin puede alcanzarse sin inconvenientes mediante la imposición de multas, tal como ha sido la tónica en jurisdicciones europeas. Prescindir de la determinación de los sujetos a indemnizar implica alterar principios arraigados en la responsabilidad civil sin que ello resulte, en modo 
alguno, imprescindible para alcanzar el fin disuasorio que a menudo se esgrime al efecto.

Ahora bien, si el legislador admite de todas formas que la determinación de los beneficiarios de una indemnización pueda pasar a un segundo plano, deben establecerse al menos mecanismos de distribución que velen por que las sumas indemnizatorias obtenidas cumplan de la mejor forma una finalidad indemnizatoria. En este sentido, las recientes experiencias legislativas de México y Chile resultan criticables en cuanto la finalidad indemnizatoria se encuentra casi totalmente ausente de los mecanismos de distribución de los montos no distribuidos, omitiendo precauciones básicas desarrolladas por el common law al aplicar la doctrina del cy-près a las acciones de clase.

\section{Referencias}

Barrientos, F. (2017). Los principales problemas de las indemnizaciones de perjuicios de los consumidores y las nuevas normas de la ley de fortalecimiento del Sernac. En Boletín Especial Adeco - Proyecto de Ley de Fortalecimiento del Sernac y las Asociaciones de Consumidores. Santiago: Universidad Diego Portales.

Boies, W. y Keith, L. (2014). Class action settlement residue and cy-près awards: Emerging Problems and practical solutions. Virginia Journal of Social Policy \& the Law, 21(2), 267-293.

Bosch, M. (2016). Netherlands. En I. Knable Gotts (ed.), The private competition enforcement review (pp. 255-175). Londres: Law Business Research.

Chasin, Ch. (2015). Modernizing class action cy-près through democratic inputs: A return to cy-près comme possible. University of Pennsylvania Law Review, (163), 1462-1495.

Comisión Europea. (2013). Recomendación 2013/396/UE.

Concina, D. (1770). Theologia christiana dogmatico-moral II. Madrid: Oficina de la Viuda de Manuel Fernández.

Congreso Nacional de Chile. (2004). Historia de la Ley 19.955. Valparaíso: Biblioteca del Congreso Nacional.

Corte de Apelaciones de Estados Unidos del Noveno Distrito. (2017). In Re Google Referrer Header Privacy Litigation, 869 F.3d 737 (9th Cir. 2017).

Corte de Distrito de Estados Unidos del Distrito Norte de California. (2015). In re Google Referrer Header Privacy Litigation, 87 F.Supp.3d 1122 (N.D. Cal., 2015). 
Corte de Distrito de Estados Unidos del Distrito Sur de Nueva York. (1074). Miller v. Steinbach, 268 F. Supp. 255 (S.D.N.Y., 1974).

Corte Suprema de Estados Unidos. (2013). Megan Marek v. Sean Lane, Statement of Roberts, C. J., 571 U. S. (2013).

Cuerdo, M. y Sánchez, D. (2014). Tradiciones penales en la maquinación para alterar el precio de las cosas del Código Penal de 1848. Anuario de Historia del Derecho Español, (84), 301-326.

De Aquino, T (1894). Summa Theologica, volumen tertium: Secunda Secundae Partis. Roma: Forzani.

De Molina, L. (1659). De Justitia et Jure. Mainz: Sumpt. Haered. Joh. Godoferdi Schönwetteri.

De Roover, R. (1951). Monopoly theory prior to Adam Smith: A revision. The Quarterly Journal of Economics, 65(4), 492-524.

Dietrich, M. y Hartmann-Rüppel, M. (2013). Germany. En I. Knable Gotts (ed.), The private competition enforcement review, pp. 194-215. Londres: Law Business Research.

Elizalde, R. y Morales, C. (2018). Los derechos difusos en México. Una mirada desde el derecho comparado. Revista de Investigación de Derecho, Criminología y Consultoría Jurídica, 12(23), 27-50.

Elsner, B., Zandler, D. y Kos, M. (2016). Austria. En I. Knable Gotts (ed.), The private competition enforcement review, pp. 49-59. Londres: Law Business Research.

Estados Unidos de América. (2017). Federal Rules of Civil Procedure. § IV, Rule 23 (Fed. R. Civ. P. 4).

Fisch, E. L. (1953). The cy-près doctrine and changing philosophies. Michigan Law Review, 51(3), 375-388.

Friedberg, E. (ed.). (1955). Corpus Iuris Canonici. [Decretum Gratiani] [Liber Sextus]. Graz: Akademische Druck- U. Verlagsanstalt.

Fuchs, A. y Vives, A. (2015). Dos problemas en torno a la responsabilidad civil derivada de ilícitos anticompetitivos. En A. Vidal Olivares (ed.), Estudios de derecho civil X (pp. 963-985). Santiago: Thomson Reuters.

Gentle, E. (2015). The cy-près distribution of a class action recovery surplus: Equity or inequity? Alabama Law Review Online, 66(1), 1-9.

Gidi, A. (2004). Las acciones colectivas y la tutela de los derechos difusos, colectivos e individuales en Brasil: un modelo para países de derecho civil. México D. F.: UNAM. Grocio, H. (1631). De iure belli ac pacis libri tres. Amsterdam: Apud Guilielmum Blaeuw.

Hallebeek, J. (1996). The concept of unjust enrichment in late scholasticism. Nijmegen: Gerard Noodt Instituut. 
Howells, G. (2011). Cy-près for consumers: Ensuring class action reforms deal with "scattered damages". En J. Steele y W. van Boom (eds.). Mass justice, challenges of representation and distribution (pp. 58-72). Cheltenham/Northampton: Elgar.

Instituto Iberoamericano de Derecho Procesal. (2004). Código modelo de procesos colectivos para Iberoamérica.

Krüger, P. (1906). Codex Iustinianus. [Codex] Berlín: Apud Weidmannos.

Lessius, L. (1610). De justitia et jure caeterisque virtutibus cardinalibus. Libro 2. París: Ex Typographia Rolini Theodorici.

Mommsen, T. y Krüger, P. (1870). Digesta Iustiniani Augusti. [Digesto] Berlín: Apud Weidmannos.

Nufer, G. (1969). Über die Restitutionslehre der spanischen Spätscholastiker und ihre Ausstrahlung auf die Folgezeit. Friburgo: Dissertationsdruck Schön.

Posner, R. (1969). Oligopoly and the antitrust laws: A suggested approach. Stanford Law Review, (21), 1562-1606.

Rodheim, A. (2017). Class action settlements, cy-près awards, and the Erie doctrine. Northwestern University Law Review, 111(4), 1097-1030.

Salinas, C. (2005). La influencia del derecho canónico en la configuración de las herencias a favor del alma en el derecho chileno. En A. Cattan Atala y A. Guzmán Brito (eds.), Homenaje a los profesores Alamiro de Ávila Martel, Benjamin Cid Quiroz, Hugo Hanisch Espindola (pp. 335-372). Santiago: Ediciones Universidad del Desarrollo.

Sande, M. J. (2018). Las acciones colectivas en defensa de los consumidores. Navarra: Thomson Reuters Aranzadi.

Shepherd, S. (1972). Comment, damage distribution in class actions: The cy-près remedy. The University of Chicago Law Review, (39), 448-465.

Shiel, C. (2015). A new generation of class action cy-près remedies: Lessons from Washington state. Washington Law Review, (90), 943-991.

Suárez, G. (2017). Perspectivas jurídicas romanas de cy-près en la órbita del stare decisis del common law angloamericano. Anuario de Historia del Derecho Español, (87), 333-376.

Tolosa, P. (2017). Acciones de clase, "microdaños" a los consumidores y fluid recovery: alternativas institucionales y costos sociales. The Latin American and Iberian Journal of Law and Economics, 3(1), 77-98.

Yale L. J. (1929). Revaluation of cy-près. Yale Law Journal,49, Issue 2, Article 6. 